\title{
Study of Prevalence Presentation and Outcome of Plasma Leakage in Dengue Fever Patients Attending Private Medical Clinic in Aden - Yemen
}

OSAM S. ABDO GABALI, M.D.

The Department of Internal Medicine, Faculty of Medicine and Health Science, Aden University

\begin{abstract}
Background: Dengue virus infections are a significant threat to human populations particularly in the tropical and subtropical regions. Aedes aegypti mosquito from humans to humans mainly transmits this. The main pathological mechanisms associated include thrombocytopenia and plasma leakage.

Aim of Study: This study aimed to describe the prevalence presentation and outcome of plasma leakage in dengue fever patients attended a private clinic in Aden - Yemen.

Patients and Methods: A retrospective study included 50 patients with dengue fever presented with fever and confirmed with positive dengue NS 1 antigen in the blood in the period from May to October 2020; all patients had done abdomen sonogram for plasma leakage features gall bladder wallo edema, ascites and pleural effusion.

Results: 50 patients were recruited in this study, male constitute $(60 \%)$ female $(40 \%),(58 \%)$ of patients came from urban areas, while (42\%) came from rural areas, $(40 \%)$ of patients had plasma leakage manifestation seen by sonogram, ( $75 \%$ ) of those patients with plasma leakage were female, ( $25 \%$ ) were male, Thick gall bladder is the most common finding in sonogram $(70 \%)$ reflecting plasma leakage, Overall mortality was $(2 \%)$ in the enrolled patients in this study.

Conclusion: Prevalence presentation and outcome of plasma leakage among dengue fever Yemeni patients do not remarkably differ from studies carried out worldwide.
\end{abstract}

Key Words: Dengue fever-Plasma leakage - Thick gall bladder.

\section{Introduction}

DENGUE is the most common and important arthropod-borne viral (arboviral) illness in humans. It is transmitted by mosquitoes of the genus Aedes, which are widely distributed in subtropical and tropical areas of the world. The incidence of dengue has increased dramatically in recent decades, with

Correspondence to: Dr. Osam S. Abdo Gabali, The Department of Internal Medicine, Faculty of Medicine and Health Science, Aden University estimates of $40 \%-50 \%$ of the world's population at risk for the disease in tropical, subtropical, and, most recently, areas that are more temperate [1].

Dengue viruses (DENV), a group of four serologically distinct but related flaviruses, are the cause of one of the most important emerging viral diseases. DENV infections result in a wide spectrum of clinical disease including dengue haemorrhagic fever (DHF), a viral haemorrhagic disease characterized by bleeding and plasma leakage. The characteristic feature of DHF is the transient period of plasma leakage and a haemorrhagic tendency. DHF occurs mostly during a secondary DENV infection. Serotype-cross reactive antibodies and mediators from serotype cross-reactive dengue specific $\mathrm{T}$ cells have been implicated in the pathogenesis. A complex interaction between virus, host immune response and endothelial cells likely affects the barrier integrity and functions of endothelial cells leading to plasma leakage [2].

In 2009, the World Health Organization (WHO) revised the classification system for dengue, defining two major entities dengue and severe dengue to replace the more complicated dengue fever / dengue haemorrhagic fever system used previously recommends classification of dengue as dengue with and without warning signs [3].

Severe dengue was defined as dengue fever with plasma leakage plus shock or fluid overload, severe bleeding or severe organ impairment [4].

Dengue fever is characterized by an initial viremic phase which corresponds to the first 3 days of illness followed by immune phase (also called critical phase) spanning from 3rd to 6th day of illness, the phase beyond 6th of illness is called recovery phase [5]. 
The most common method of monitoring leakage relies on identification of relative haemoconcentration, determined by tracking changes in serial haematocrit measurements, with a rise of more than $20 \%$ from baseline considered evidence of significant leakage. However, this method can be rather insensitive, particularly if the patient is receiving parenteral fluid therapy, and it is limited by the fact that an individual's baseline value is rarely known [6].

Studies using ultrasound have demonstrated that pleural effusions, ascites and gall bladder wall oedema are common during the critical phase, and correlate with disease severity $[\mathbf{7 , 8 ]}$.

In addition, serial ultrasound studies is better at predicting likely disease progression than other markers of plasma leakage such as haematocrit and albumin measurements [9].

Aim of work:

To study prevalence of plasma leakage in dengue fever patients attended a private clinic.

\section{Material and Methods}

This was a retrospective study carried out in a private clinic in Aden, Yemen, included 50 patients with dengue fever during 4 months interval in the period from May to October 2020.

All patients with fever, positive dengue NS 1 antigen included in the study.

All patients had done abdomen sonogram for plasma leakage features, evidence of plasma leakage as indicated by the presence of thick gall bladder (wall of gall bladder is considered thick if it is $>3 \mathrm{~cm}$ ), pleural and/or ascitic fluid as mentioned in Organization WH. Dengue Haemorrhagic Fever: diagnosis, treatment, prevention and control. 2. WHO; 1997.

Patients excluded from study if they have previous gall bladder disease, hepatic disease or, pulmonary diseases associated with pleural effusion.

The following data were collected from allpatients included in this study:

$1-$ Sex.

2- Residency distribution.

3- Radiological investigation: Abdomen ultrasonography.

Computer analysed the data and because the population was small, the result was, the result was calculated manually and presented as mean, percentage and tables as appropriate.
Ethical consideration: Verbal informed consent was obtained from all participating subjects.

\section{Results}

50 subjects were recruited into study.

The sex distribution in Table (1) showed a prominence of male gender $(60 \%)$ among dengue fever patients enrolled in this study versus $(40 \%)$ being female.

Table (1): The sex distribution.

\begin{tabular}{lcc}
\hline Sex & No. of patients & $\%$ \\
\hline Male & 30 & 60 \\
Female & 20 & 40 \\
\hline
\end{tabular}

Table (2): Showed residency distribution revealed that majority residing in urban areas.

\begin{tabular}{ccc}
\hline Residency & No. of patients & $\%$ \\
\hline Urban area & 29 & 58 \\
Rural area & 21 & 42 \\
\hline
\end{tabular}

$58 \%$ of dengue fever patients included in this study came from urban areas.

Table (3): Showed prevalence of plasma leakage among dengue fever patients.

\begin{tabular}{lcc}
\hline DF & No. of patients & $\%$ \\
\hline Plasma leakage & 20 & 40 \\
No plasma leakage & 30 & 60 \\
\hline
\end{tabular}

$40 \%$ of enrolled patients had plasma leakage confirmed by ultrasound.

Table (4): Sex distribution among patients with plasma leakage.

\begin{tabular}{ccc}
\hline DF with plasma leakage & No. of patients & $\%$ \\
\hline Male & 5 & 25 \\
Female & 15 & 75 \\
\hline
\end{tabular}

Incidence of dengue fever with plasma leakage among female $(75 \%)$ was greater than male $(25 \%)$.

Table (5): Showed ultrasonography findings in dengue fever cases with plasma leakage (many patients have more than one sonographic finding).

\begin{tabular}{lcc}
\hline DF with plasma leakage & No. of patients & $\%$ \\
\hline Gallbladder wall thickening & 14 & 70 \\
Ascites & 10 & 50 \\
Pleural effusion & 3 & 15 \\
\hline
\end{tabular}


In our study, thick gall bladder was the commonest Ultrasonography Findings in Dengue Fever Cases with plasma leakage (70\%).

Table (6): Showed outcome in the dengue fever cases.

\begin{tabular}{ccc}
\hline Outcome & No. of patients & $\%$ \\
\hline Alive & 49 & 98 \\
Dead & 1 & 2 \\
\hline
\end{tabular}

In our study one patient (2\%) died from 50 patient recruited, the patient had plasma leakage manifestation.

\section{Discussion}

50 subjects were recruited into study, The sex distribution in Table (1) showed a prominence of male gender $(60 \%)$ among dengue fever patients enrolled in this study versus (40\%) being female.

It was approximately near the percentage of male $(57 \%)$ obtained by Mallhi et al., study in Malaysia at 2015 [10], and greater than $(50.8 \%)$ male percentage found in the study of Prediction of plasma leakage phase of dengue in resource limited settings done in Sri Lanka by Herath et al., in 2019 conducted in National Hospital of Sri Lanka [11].

$58 \%$ of dengue fever patients included in this study came from urban areas, Close to the result of $60.4 \%$ mentioned in the study of Mallhi et al. [10].

$40 \%$ of enrolled patients had plasma leakage confirmed by ultrasound, this result was close to Herathetal study named Prediction of plasma leakage phase of dengue in resource limited settingscarried out at the National Hospital, Sri Lanka where $(38.7 \%)$ in his study had ultrasonography evidence of plasma leakage during the course of the illness [11].

Incidence of dengue fever with plasma leakage among female $(75 \%)$ was greater than male $(25 \%)$, Chakravarti, et al., study in India at 2016 also shown greater incidence of plasma leakage among female dengue fever [12].

In contrast to the study executed by Cambridge university in September 2016 in Brazil which shown higher prevalence in male rather than female [13].

Thickening of the gallbladder considered $>3 \mathrm{~cm}$.
In our study, thick gall bladder was the commonest Ultrasonography Findings in Dengue Fever Cases with plasma leakage (70\%).

Many studies were in concordance with the findings of our study with thickening of gall bladder as the most common finding in their studies.

Joshi P who reported an incidence of $72 \%$ of gall bladder wall thickness in his study published in the Indian Journal of Radiology and Imagining [14].

Among the Ultrasonography findings reported, in In Manam, et al., study conducted in India in 2018, Published in International Journal of Contemporary Medicine Surgery and Radiology thickness of the gall bladder wall was the commonest finding with $65.08 \%$ followed nearby with Ascites with $62.70 \%$ and pleural effusion (49.21\%) [15].

In our study one (2\%) patient died from 50 patient recruited in the study this patient had plasma leakage manifestation.

Close to, the eight patients (1.2\%) died during study period of Mallhi et al., study in Malaysia [10].

\section{References}

1- World Health Organization, dengue and severe dengue fact sheet. WHO. Available at http://www.who.int. April 2017.

2- ANON SRIKIATKHACHORN M.D.: Plasma Leakage in Dengue Haemorrhagic Fever, Thromb Haemost, 102 ( 6): (1042-1049). December 2009.

3- World Health Organization, Dengue guideline for diagnosis treatment prevention and control, New edition Geneva. Available at http: //www.who.int. (1-160) 2009.

4- World Health Organization and the special Programme for research and training in tropical diseases (TDR). Dengue guidelines for diagnosis, prevention and control, new edition. 1st edition; 2009.

5- EMMANUEL BHASKARA, RAVEENDRAN PRAVEENAB, GOPALAN SOWMYAA and SWATHY MOORTHYA: Salvador categorization of dengue fever according to phase of illness a suggestion for clinical studies using single diagnostic sample. Braz. Infect Dis., 17 (5): 622-623, Sept/Oct., 2013.

6- SOPHIE YACOUB and BRIDGET WILLS: Predicting outcome from dengue, BMC Medicine, 12 (1): 147, 2014.

7- BHARATH KUMAR REDDY K.R., LAKSMANA R.R. and VEERAPPA B.G.: Shivananda: Ultrasonography as a tool in predicting the severity of dengue fever in children-a useful aid in a developing country. Pediatr. Radiol., 43:971-977, 2013.

8- COLBERT J.A., GORDON A., ROXELIN R., SILVA S., SILVA J., ROCHA C. and HARRIS E.: Ultrasound measurement of gall bladder wall thickening as a diagnostic 
test and prognostic indicator for severe dengue in paediatric patients. Pediatr. Infect Dis. J., 26: 850-852, 2007.

9- MICHELS M., SUMARDI U., DE MAST Q., JUSUF H., PUSPITA M., DEWI I.M., SINARTA S., ALISJAHBANA B. and VAN DER VEN A.J.: The predictive diagnostic value of serial daily bedside ultrasonography for severe dengue in Indonesian adults. PLoS Negl. Trop. Dis., 7: e2277, 2013

10- TAUQEER HUSSAIN MALLHI, AMER HAYAT KHAN, AZREEN SYAZRIL ADNAN, AZMI SARRIFF, YUSRA HABIB KHAN and FAUZIAH JUMMAAT: Clinicolaboratory spectrum of dengue viral infection and risk factors associated with dengue haemorrhagic fever: BMC Infectious Diseases 15:399 DOI 10.1186/s12879-0151141-3, 2015.

11- H.M.M.T.B. HERATHA, W.A.E. UDESHIKAA, S.S.M. SAMARAWICKRAMAA, NILUKSHANA YOGENDRANATHANA, W.D. JAYAMALIA, ARUNA KULATUNGAA and CHATURAKA RODRIGO: Predictionof plasma leakage phase of dengue in resource limited settings. Clinical Epidemiology and Global Health, 7: 279-282, 2019.
12- A. CHAKRAVARTI, P. ROY, S. MALIK, O. SIDDIQ and P. THAKUR: A study on gender related differencs in laboratory characteristics of dengue fever, Indian Journal of Medical Microbiology, Volume: 34, Issue one page 82-84, 2016.

13- C.R. VICENTE, C. CERUTTI JUNIOR, G. FROSCHL, C. M.ROMANO, A.S.A. CABIDELLE and K.H. HERBINGER: Influence of demographics on clinical outcome of dengue: Cross sectional study of 6703 confirmed cases in vitoria, espirito santo state, Brazil, Published online by Cambridge University Press: Volume 145 Issue 1/09September 2016.

14- JOSHI P., RATHNAM V.G. and SHARMA S.: USG findings in dengue haemorrhagic fever - our experience in the recent epidemic. Ind. J. Radiol. Imag., 7 (4): 18992, 1997.

15- GAYATRI MANAM, RAVI M. GODAVARTHI, RAMAKRISHNA BARU, SUNITHA and GOWTHAM SURYA DUDDU: Evaluation of Ultrasonography Findings in Dengue Fever Cases during an Outbreak at a Tertiary Care Hospital of South India, International Journal of Contemporary Medicine Surgery and Radiology, 3 (2): 106-110, 2018.

\section{دراسة انتشار وظهوروتتيجة تسرب البلازما

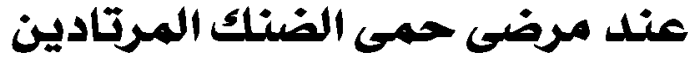

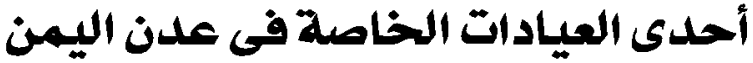

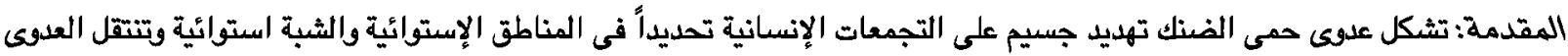

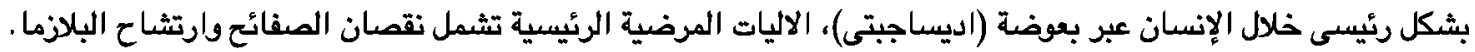

الأهداف: تهدف هذه الدراسة لوصف انتشار، ظهود ونتيجة ارتشاحاً لبلازما عند مرضى حمى الضنك المرتادين أحدى العيادات الخاصة فى عدن اليمن.

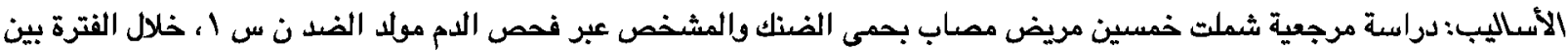

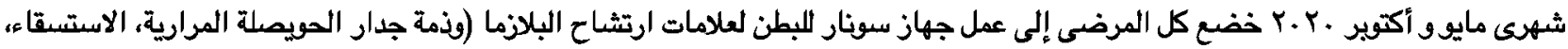

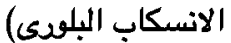

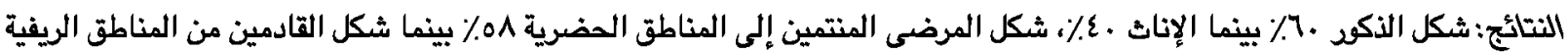

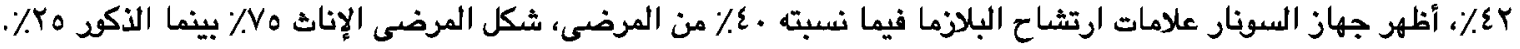
شكل زيادة سماكة الحوصلة المرارية ما نسبته . ٪\% من نتائج جهاز السونار وهى الاكثر شيوعاً من علامات ارتشاح البلازما. معدل الوفيات شكل ب/\% من الحالات المشملة فى هذا البحث. الخلاصة: انتشار وظههد ونتيجة ارتثاح البلازما عند مرضى حمى الضنك اليمنيين لا يختلف عن الأبحاث الأخرى التى جريت فى العالم. 